\title{
Determination of Optimum Cement Content for Stabilization of Soft Soil and Durability Analysis of Soil Stabilized with Cement
}

\author{
Md Ali Ashraf, S. M. Shazeebur Rahman*, Md Omar Faruk, Md Abul Bashar \\ Department of Civil Engineering, Southern University Bangladesh, Chittagong, Bangladesh \\ Email address: \\ ashraf.engr.66@gmail.com (Md A. Ashraf), shazeeburrahman049@gmail.com (S. M. S. Rahman), \\ omarfarukcity0901@gmail.com (Md O. Faruk), and eng.bashar31@gmail.com (Md A. Bashar) \\ ${ }^{*}$ Corresponding author
}

\section{To cite this article:}

Md Ali Ashraf, S. M. Shazeebur Rahman, Md Omar Faruk, Md Abul Bashar. Determination of Optimum Cement Content for Stabilization of Soft Soil and Durability Analysis of Soil Stabilized with Cement. American Journal of Civil Engineering. Vol. 6, No. 1, 2018 , pp. 39-43. doi: $10.11648 /$ j.ajce.20180601.17

Received: December 4, 2017; Accepted: December 18, 2017; Published: January 5, 2018

\begin{abstract}
This research was aimed at finding the optimum cement content for achieving maximum compressive strength and stabilization in soft soil found in the periphery of the city of Chittagong. But, gaining strength was not considered enough unless it can be proved that strength was gained without compromising the durability. As such, durability test was performed on the samples stabilized with different percentages of cement. In this research three different soil samples were used. The samples were collected from three different areas within the city where future expansion of the city is expected. Six different percentages of cement by weight of soil: $0 \%, 2 \%, 4 \%, 6 \%, 8 \%$, and $10 \%$ were used. Cement was mixed with soil at optimum moisture content. Cubes were casted and their compressive strengths assessed after a curing period of $7,14 \& 28$ days. The durability test was done in two different cycles: 2 days wetting-drying and 7 days wetting-drying within a time frame of 28 days. The volume and weight were monitored after completion of each cycle of wetting and drying. The performance of the soils modified with different percentages of cement were assessed using Standard Proctor Test, Unconfined Compression Test and Durability Test. It was found that compressive strengths in the samples under test increased with the increase of cement content up to $8 \%$. But when cement content is increased above $8 \%$, the compressive strength increased but in a slower rate. At the end of durability test, it was observed that volume, and weight of the soil samples produced with 2,4 and $6 \%$ cement changes with the variation in wetting and drying periods. But when the cement percentage is increased by $6 \%$, preferably increased to $8 \%$, no appreciable change in weight and volume were observed after the wetting and drying cycles. The samples going through the two days wetting and drying cycles under durability test showed greater unconfined compressive strength compared to samples going through seven days durability cycle of wetting and drying. It may be mentioned here that the three soil samples stabilized with cement did not show any major degradation in compressive strength during durability test.
\end{abstract}

Keywords: Standard Proctor Test, Unconfined Compressive Strength, Durability, Wetting- Drying, Stabilization

\section{Introduction}

Soil stabilization is the process of improving the engineering properties of the soil thus making it more stable. Insufficient strength or insufficient deformation resistance is a problem of soil in many forms of construction such as, buildings, airfields, tunnels, dams, roads, trafficked areas etc. and can lead to very serious economic loss, environmental hazards, etc.
Stabilization techniques can be used to treat a wide range of soils from expansive clays to sands. This allows for the establishment of design criteria as well as the determination of the proper chemical additive and admixture rate to be used in order to achieve the desired engineering properties. Benefits of the stabilization process can include higher resistance values, a reduction in plasticity, lower permeability, reduction of pavement thickness, elimination of excavated material hauling or handling. Stabilization of 
expansive soils with admixtures controls the potential of soils for a change in volume, and improves the strength of soils, in the field of Geotechnical engineering. [1]

Sometimes roadway or flexible pavement fails due to low strength failure of subgrade materials. If the strength of subgrade materials can be increased, then road pavement will not fail. In Chittagong city and in the surrounding villages subgrade soils are generally silty /clayey or show high plasticity that means it will allow more deformation before carrying ultimate load. In such a situation, deep foundation is generally thought of but that will be costlier compared to shallow foundation. An alternative low-cost solution, therefore, is to be explored. After stabilization of subgrade soil, a low-rise building can be constructed with low cost shallow foundation; effectively and economically.

Whatever stabilization we do, it is to be checked for durability before implementation in the field. The word durability originates from the Latin word 'durabilis' which means 'lasting'. Durability is the ability to last a long time without significant deterioration. A durable material helps the environment by reducing wastes and by minimizing the cost of repair and maintenance. The degree of durability is based on the performance as defined by resistance to moisture absorption, resistance to strength reduction during and wetting and drying cycles. Poor soil does not sustain the effects of environmental forces, such as wetting-drying cycles. [2]

\section{Methodology}

\subsection{Material Properties}

Three soil samples were collected from Bandartila (S-1), Mohora (S-2) and Khulshi hills (S-3) of Chittagong for this research. S-1 and S-2 are almost identical in terms of soil properties and grain sizes. The results of the physical identification tests for all the aforementioned three soil samples are shown in Table 1.

Table 1. Physical parameters of soil samples.

\begin{tabular}{|c|c|c|c|c|c|c|}
\hline Soil Sample & MIT classification & Specific Gravity (G) & Liquid limit ( $\left.w_{l}\right)$ & Plastic limit $\left(w_{p}\right)$ & Plasticity index $\left(I_{p}\right)$ & Salinity \\
\hline S-1 & Sandy silt and some clay & 2.5 & $26 \%$ & $20.45 \%$ & $5.55 \%$ & $3 \%$ \\
\hline S-2 & Sandy silt and some clay & 2.5 & $25.5 \%$ & $20.00 \%$ & $5.50 \%$ & $0 \%$ \\
\hline S-3 & Silty sand and some gravel & 2.67 & -- & -- & -- & $0 \%$ \\
\hline
\end{tabular}

Bandartilla in the southern part of the city is near the coast line; therefore, a little percentage of salinity may be expected in this type of soil. Diamond cement, a composite cement, purchased from the local market was used as a binder for enhancing the compressive strength / load bearing capacity of the soil. According to their literature, the compressive strength of the cement at 3, 7 and 28 days are 2.57, 3.56 and $5.9 \mathrm{ksi}$ respectively. Initial and final setting time of the cement are 162 and 353 minutes respectively. Fineness of the cement was found recorded as $353 \mathrm{~m}^{2} / \mathrm{kg}$.

\subsection{Experimental Program}

For the laboratory tests, locally available cement; in this case Diamond Brand Cement, was considered a candidate stabilizer to treat / stabilize the soil samples. Experiments with different percentages of cement: $0 \%, 2 \%, 4 \%, 6 \%, 8 \%$ and $10 \%$ were used to identify the optimum cement content for gaining maximum compressive strength with durable subgrade at a low affordable cost. Cement stabilization is the densification of soil via applying mechanical energy in order to remove air from the soil mass. In this study "standard compaction test" were applied for investigation the effect of different combination of cement on the soil behavior. Standard compaction test described in the AS1289.5.5.1 (ASTM D 698) [3] was performed to determine the maximum dry density (MDD) and the optimum moisture content (OMC) of the soils.

Unconfined Compression Test (UCT) samples were prepared at the optimum moisture contents determined from the compaction curves. The UCS tests were carried out on cylindrical specimens, having a length of $76 \mathrm{~mm}$ and a diameter of $38 \mathrm{~mm}$, by following ASTM D 2166-98. [4] The prepared UCT samples were sealed in a plastic bag to cure in the humidity room where the temperature was maintained at $20 \pm 2{ }^{\circ} \mathrm{C}$ for 7,14 and 28 days before conducting the test. Unconfined compression tests were conducted on a straincontrolled tri-axial testing frame at a strain rate of $1 \% / \mathrm{min}$ without application of the cell pressure $\left(\sigma_{3}=\right.$ zero). The maximum load was converted to the unconfined compression strength of the sample.

The durability test was used to ensure sustainability of the strength of the modified soil. The test is conducted according to ASTM D 559-96 standard test method [5]. Samples were prepared with varying cement contents mentioned above. A set of two specimens were prepared for each mix specifications. These specimens were prepared with cement mixed with soil at its optimum moisture content; obtained from the Proctor Compaction Test. The test requires measurements and sample handling for each cycle of wetting and drying procedures. Two different cycles were considered for this study; 2 days wetting- drying and 7 days wettingdrying for a curing period of 28 days.

\section{Result and Discussion}

\subsection{Physical Properties of the Soil Samples}

Results of the physical parameter tests conducted on the soil samples are presented in Table 1.

From the particle size analysis, it is found that, S-1 sample had a sand content of about $38 \%$, silt content of $47 \%$ and clay content of about $15 \%$. In S-2 sample, the contents of sand, silt and clay were $39 \%, 49 \%$ and $12 \%$ respectively. For 
S-3 soil sample, these percentages of sand, silt and clay change to $90 \%, 8 \%$ and $0 \%$ respectively with around $2 \%$ gravel in it.

\subsection{Compaction Characteristics of Stabilized Soil}

The soil particles are reorganized during the compaction process through water, cement and the external energy. Figure 1, Figure 2 and Figure 3 illustrate the compaction properties of soil (S-1, S-2 and S-3) with varying cement mixtures. The adjustment in composition of the stabilized mixtures reflected in the changes in the maximum dry unit weight and the optimum moisture content.

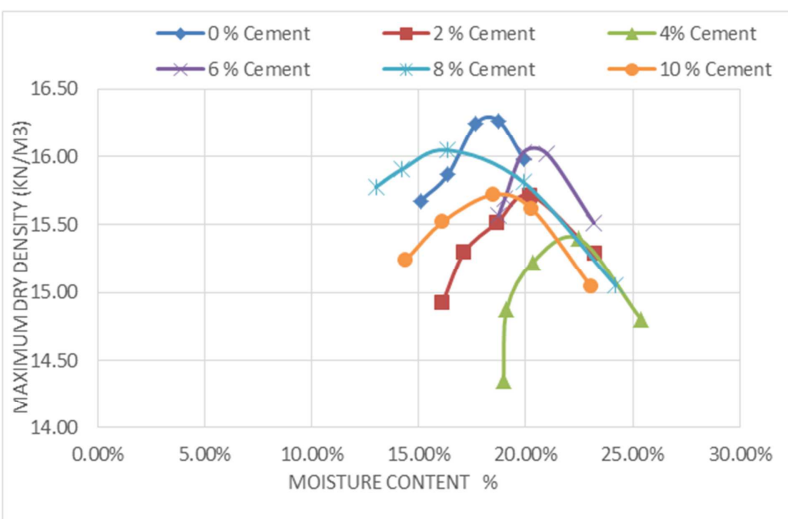

\begin{tabular}{|c|c|c|}
\hline $\begin{array}{c}\text { \% of } \\
\text { Cement }\end{array}$ & $\begin{array}{c}\text { OMC } \\
(\%)\end{array}$ & $\begin{array}{c}\text { MDD } \\
\left(\mathbf{k N} / \mathbf{m}^{3}\right)\end{array}$ \\
\hline $\mathbf{0}$ & 18.73 & 16.27 \\
\hline $\mathbf{2}$ & 20.23 & 15.71 \\
\hline $\mathbf{4}$ & 22.49 & 15.40 \\
\hline $\mathbf{6}$ & 19.89 & 16.03 \\
\hline $\mathbf{8}$ & 16.32 & 16.05 \\
\hline $\mathbf{1 0}$ & 18.47 & 15.72 \\
\hline
\end{tabular}

Figure 1. Compaction curve of S-1 sample with different cement contents.

Maximum dry density (MDD) and Optimum moisture content (OMC) of the soil sample S-1 is $16.27 \mathrm{kN} / \mathrm{m}^{3}$ and $18.73 \%$ respectively with zero percent cement. The MDD lowers when the OMC increases with the addition of cement up to $4 \%$. At this percentage of cement, the MDD value is $15.4 \mathrm{kN} / \mathrm{m}^{3}$ with a corresponding OMC value is $22.49 \%$. With further addition of cement content, condition reverses.
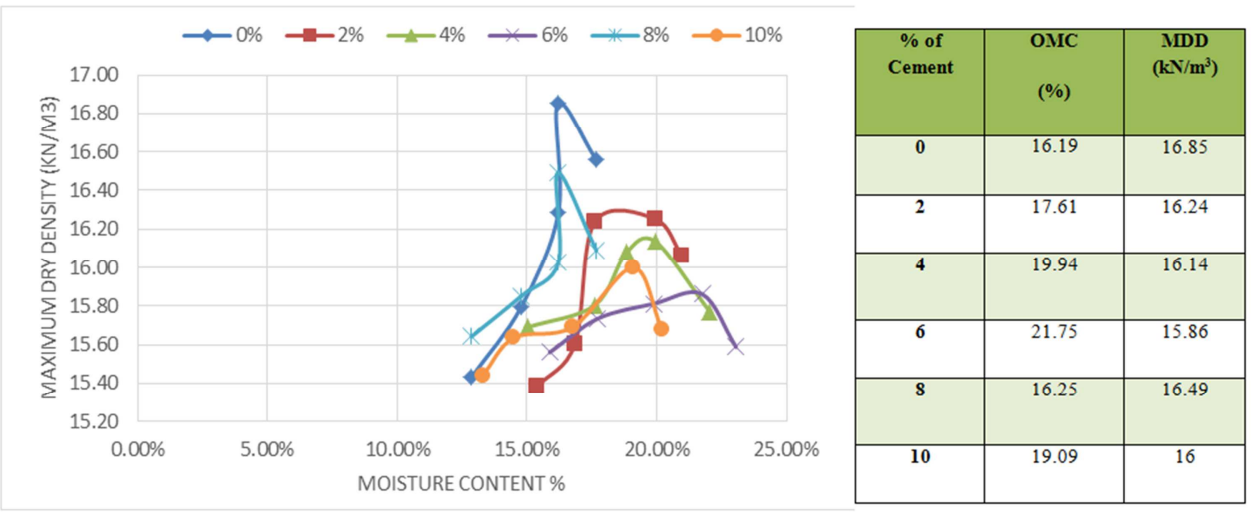

Figure 2. Compaction curve of S-2 sample with different cement contents.

In case of soil sample $\mathrm{S}-2$, the controlled MDD value is $16.85 \mathrm{kN} / \mathrm{m}^{3}$ and OMC value is $16.19 \%$ with zero \% cement. OMC goes up to $21.75 \%$ and MDD declines to $15.86 \mathrm{kN} / \mathrm{m}^{3}$ for an addition of $6 \%$ cement with the soil. Further addition of cement OMC gets reduced and MDD increased.

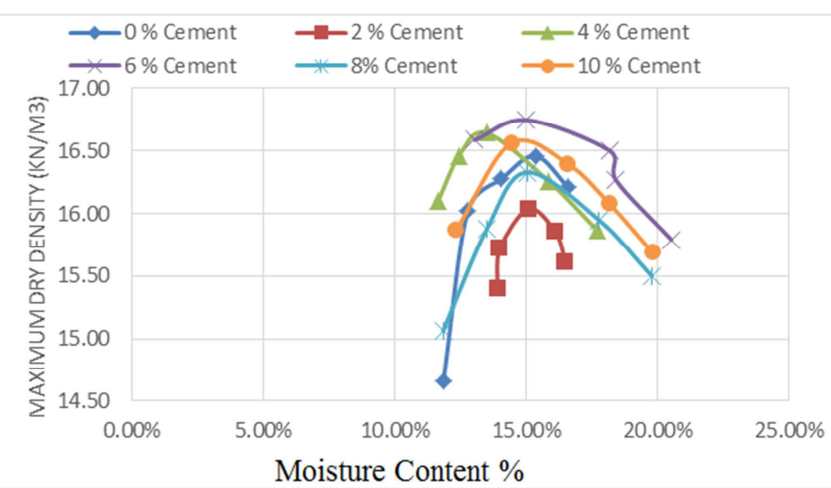

\begin{tabular}{|c|c|c|}
\hline $\begin{array}{c}\text { \% of } \\
\text { Cement }\end{array}$ & $\begin{array}{c}\text { OMC } \\
\mathbf{( \% )}\end{array}$ & $\begin{array}{c}\text { MDD } \\
\mathbf{( k N / \mathbf { m } ^ { 3 }} \mathbf{)}\end{array}$ \\
\hline $\mathbf{0}$ & 13.09 & 16.4 \\
\hline $\mathbf{2}$ & 14 & 16.46 \\
\hline $\mathbf{4}$ & 15 & 16.64 \\
\hline $\mathbf{6}$ & 15.43 & 16.7 \\
\hline $\mathbf{8}$ & 15.03 & 16.33 \\
\hline $\mathbf{1 0}$ & 14.44 & 16.56 \\
\hline
\end{tabular}

Figure 3. Compaction curve of S-3 sample with different cement contents and variation. 
For sample S-3, OMC was $13.09 \%$ and MDD was 16.4 $\mathrm{kN} / \mathrm{m}^{3}$ for the control soil with zero cement. If cement is added up to $6 \%$ the OMC changes from the controlled value to $15.43 \%$ and the corresponding MDD becomes $16.7 \mathrm{kN} / \mathrm{m}^{3}$.

\subsection{Strength Characteristics of Soil-Cement Stabilization}

Time-strength development is crucial in the study of strength characteristics of soils treated with stabilizers as the structure of such materials evolves with time due to continuing hydration/ pozzolanic reactions ([7], [8], [9], [10]). To illustrate the strength evolution soil specimens treated with $2 \%, 4 \%, 6 \%$, $8 \%$ and $10 \%$ cement, the stress-strain response was recorded for each of the mixtures which were cured for $0,7,14$ and 28 days to produce the stress-strain curves.

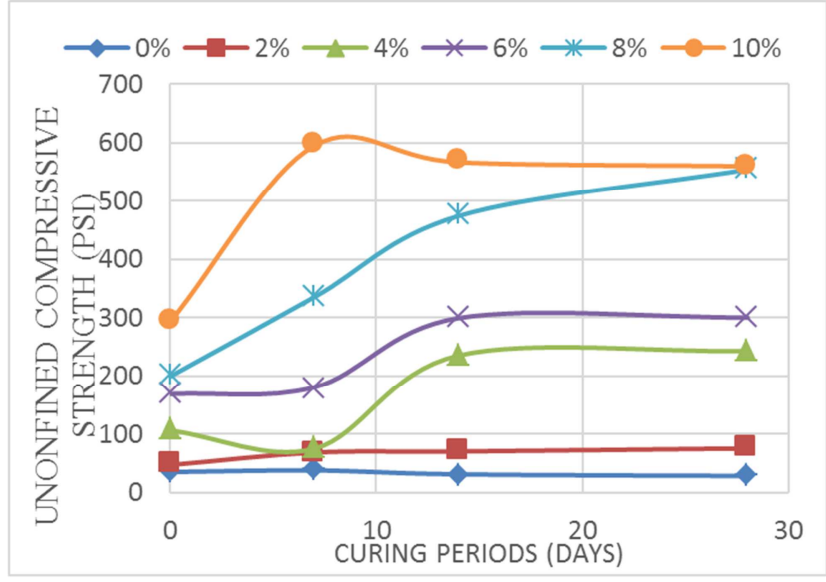

Figure 4. Variation of strength with curing period of S-1.

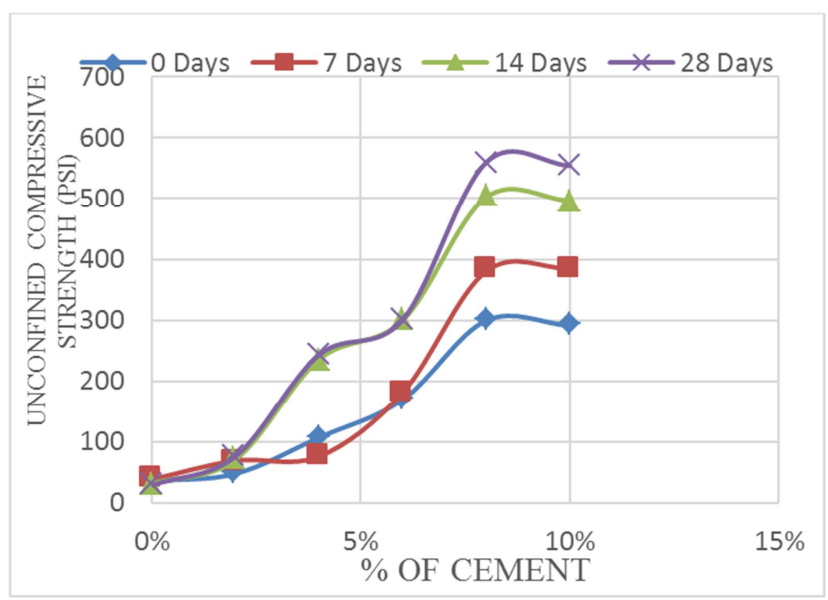

Figure 5. Variation of strength with\% of cement of S-1.

In S-1 soil sample (Collected from Bandartilla), the maximum strength after 28 days curing is found with $8 \%$ cement, which is about 36 ton /sq.ft, approximately 15 times greater than the compressive strength of control soil with $0 \%$ cement. Compressive strength of control soil with $0 \%$ percent cement was 2.37 ton/sq.ft. With further increase in cement percent, the rate of growth in compressive strength decreased by $0.98 \%$ compared to $8 \%$ cement.

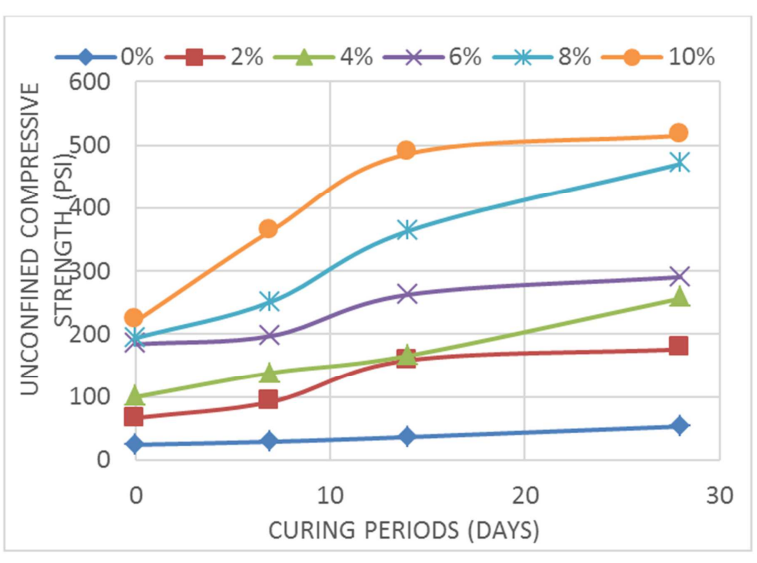

Figure 6. Variation of strength with curing period of $S-2$.

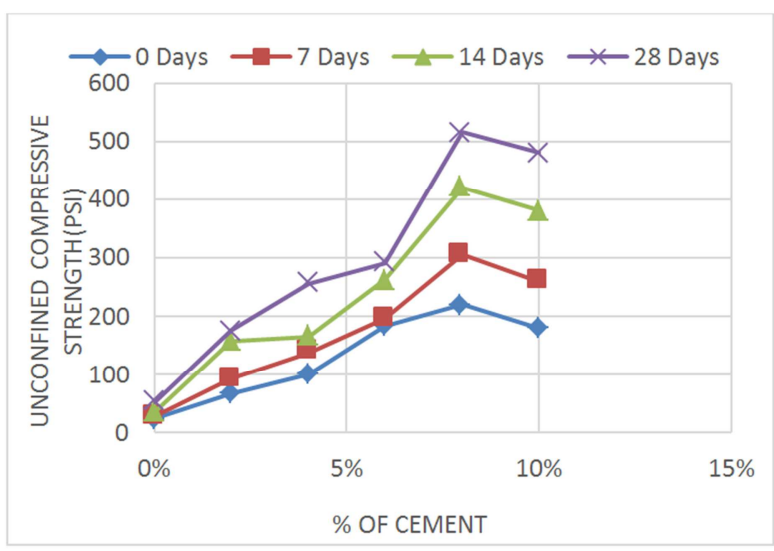

Figure 7. Variation of strength with\% of cement of S-2.

In $\mathrm{S}-2$ soil sample (Collected from Mohara), the maximum strength of 33.10 ton/sqft after 28 days curing period was found with $8 \%$ cement, which are 16 times greater than the compressive strength ( $2 \mathrm{ton} / \mathrm{sqft}$ ) of control soil with $0 \%$ cement. If percentage of cement is increased further, the rate of increase in compressive strength gets reduced compared to the strength of $8 \%$ cement. It is evident from the graph that up to the addition of $8 \%$ cement, the rate of gain in strength was almost uniform.

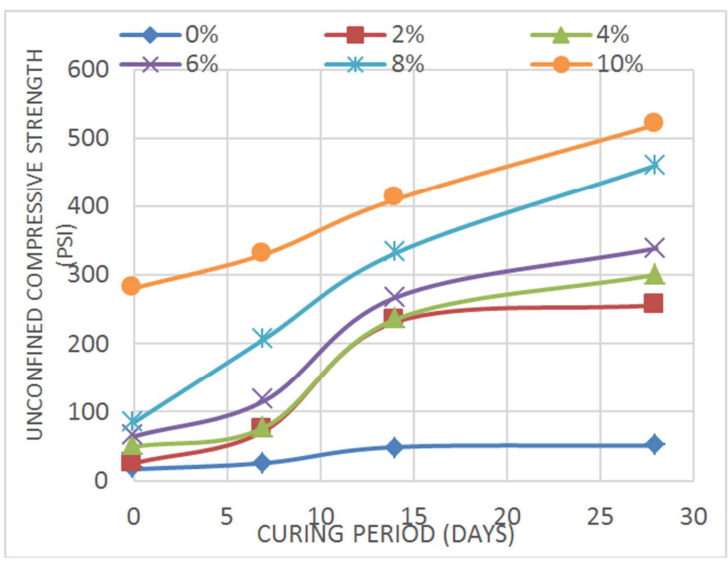

Figure 8. Variation of strength with curing period of S-1. 


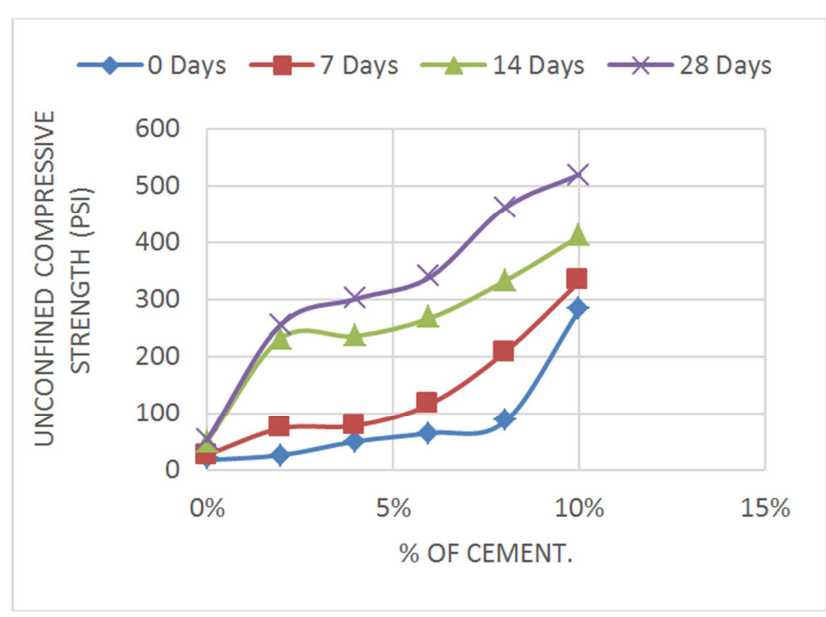

Figure 9. Variation of strength with\% of cement of S-1.

In S-3 soil sample (Collected from Khulshi hills), the maximum strength was 33.45 ton/sq ft after 28 days of curing period with an addition of $10 \%$ cement. The maximum strength is around 25 times larger than the compressive strength of control soil with $0 \%$ cement. Compressive strength of control soil with $0 \%$ cement $=1.35$ ton $/ \mathrm{sq} \mathrm{ft}$. With further increase of cement content, the strength increases further significantly. It is evident from the graph that up to the addition of $2.5 \%$ cement, compressive strength gained at a uniform rate. But beyond $2.5 \%$ cement, with further addition of cement, gain was there but the gain took place at a reduced rate of increment. Even with the addition of $2.5 \%$ cement, compressive strength was about 18 ton per sq. $\mathrm{ft}$ compared to 1.35 ton per sq.ft in control soil sample with $0 \%$ cement. The gain is around 13 times over the control sample. Therefore, it can be said that the most economical percentage of cement for gaining a reasonable increase in compressive strength will be $2.5 \%$ in sandy hill soil. But it is to be looked into whether the soil samples with the addition of a minimum cement of $2.5 \%$ of the weight of soil, will be durable or not.

\subsection{Durability Characteristics}

After completion of 7 days cycle of wetting, all the three samples with no cement could not retain shape and spread flat. A slight change in volume and weight was found with cyclic wetting and drying of the soil samples with cement percentages of $2 \%, 4 \%$ and $6 \%$. But the volume and weight of the samples remained almost same with 8 and $10 \%$ cement. During durability tests, the 2 days cycled sample provides higher unconfined compressive strength (UCS) compared to the 7 days cycled sample. That means with long period of weathering strength decreases.

\section{Conclusions}

Generally, with the addition of 8 to $10 \%$ cement in the soil predominantly sand or sandy silt, unconfined compressive strength increases 11 to 12 times over the control sample of soil with $0 \%$ cement in it. This information can be used effectively in reducing the cost of foundation.

For example, Bandartilla soil in Halishahar, Chittagong has Unconfined Compressive Strength of 2.37 tons /sq.ft and 36 tons /sq.ft for soils with $0 \% \& 10 \%$ cement respectively.

If we use safety factor 3 , then the strengths for $0 \%$ and $10 \%$ cement will be 1.09 ton/sq.ft \& 11.15 tons/sq.ft. respectively. Improvement in strength is around 10 times the strength with zero percent cement. This will allow a designer to use shallow foundation in place of deep foundation for a structure which eventually will reduce the foundation cost drastically.

In road construction, soil bearing capacity improved like this will give very high CBR value. With high CBR value for sub grade/sub base, height of embankment can be drastically reduced which will reduce the cost of road construction, eventually.

\section{References}

[1] Dr. Arora K. R, 2006. Soil Mechanics and Foundation Engineering. 376p.

[2] Ibrahaim M. Al-Kiki, Moafaq A. Al-Atalla \& Abdulrahman H. Al-Zubaydi., 2011. Durability test of stabilized soil. Eng. \& Tech. Journal, Vol. 29, No. 4.

[3] ASTM D 698, 2000, Standard Test Methods for Laboratory Compaction Characteristics of Soil Using Standard Effort.

[4] ASTM D 2166-98, 2000, Standard Test Method for Unconfined Compressive Strength of Cohesive Soil.

[5] ASTM D 559-96, 1996, Standard test methods for wetting and drying compacted soil-cement mixtures.

[6] T. Kamei, A. Ahmed, K. Ugai, 2013, Durability of soft clay soil stabilized with recycled Bassanite and furnace cement mixtures, The Japanese Geotechnical Society, 53(1):155 - 165

[7] Al-Refeai, T. O., Al-Karni, A. A., 1999. Experimental study on the utilization of cement kiln dust for ground modification. King Saud Univ. Eng. Sci. 11 (2), 217-232.

[8] Oriola, F., Moses, G., 2011. Compacted black cotton soil treated with cement kiln dust as hydraulic barrier material. Am. J. Sci. Indust. Res. 2(4), 521-530.

[9] Peethamparan, S., Olek, J., 2008. Study of the effectiveness of cement kiln dusts in stabilizing N-montmorillonite clays. J. Mater. Civ. Eng. 20 (2), 137-146.

[10] Salahudeen, A. B., Eberemu, A. O., Osinubi, K. J., 2014. Assessment of cement kiln dust-treated expansive soil for the construction of flexible pavements. Geotech. Geol. Eng. http://dx.doi.org/10.1007/s10706-014-9769-0 (Springer International Publishing Switzerland). 